8. Андреев Е.М., Дарский Л.Е., Харькова Т.Л. Демографическая история России: 1927-1957. М.: Информатика, 1998. 197 с.

9. Жиромская В.Б. Основные тенденции демографического развития России в XX веке. М.: Кучково поле, 2012. 320 с.

10. Исупов В.А. Эпидемический переход в России: взгляд историка // Демографическое обозрение. 2016. Т. 3, № 4. С. 82-92.

11. Семенова В.Г. Обратный эпидемиологический переход в России. М.: ЦСП, 2005. 235 с.

12. Народное хозяйство РСФСР за 70 лет: Статистический ежегодник. М.: Финансы и статистика, 1987. $471 \mathrm{c}$.

13. Большая медицинская энциклопедия / под ред. Б.В. Петровского, 3-е издание в 30-ти томах, М.: «Советская энциклопедия», 1974-1989 гг.

14. Носов С.Д. Детские инфекционные болезни. М.: Медицина, 1973. 535 с.

15. Шувалова Е.П. Инфекционные болезни. М.: Медицина, 1990. 560 с.
16. Заблудовский П.Е., Крючок Г.Р., Кузьмин М.К., Левит М.М. История медицины. М.: Медицина, 1981. $352 \mathrm{c}$.

17. Репинецкий А.И., Румянцева М.А. Городское население Среднего Поволжья в послевоенное двадцатилетие. 1945-1965 гг.: Очерки демографической истории. Самара: Изд-во «НТЦ», 2005. 262 с.

18. Румянцева М.А. Городское население Среднего Поволжья в 1956-1965 гг. Материалы к изучению демографической истории: сборник материалов и документов. Самара: СамГТУ, 2012. 176 с.

19. Инструктивно-методические указания по диагностике, лечению и профилактике чумы: инструкция Минздрава СССР // Сб. норм. док. по сан.-противоэпидем.режиму. Т. II .М.: Агар, 1996.

20. Бадугинова М.В. Борьба со вспышкой эпидемии чумы в Калмыцкой АССР и Сталинградской области в 1937-1938 гг. // Вестник Калмыцкого ин-та гуманитарных исследований РАН. 2012. № 2. С. 108-113.

21. Васильев К.Г., Сегал А.Е. История эпидемий в России. М.: Медгиз, 1960. 398 с.

\title{
THE DEVELOPMENT OF MEDICINE AS A FACTOR OF «EPIDEMIC TRANSITION» IN THE URBAN POPULATION OF THE MIDDLE VOLGA REGION
}

\author{
Rumyantseva Maria Aleksandrovna, candidate of historical sciences, associate professor, \\ researcher of Economics and Management Department \\ Branch of Samara State Technical University in Novokuibyshevsk \\ (Novokuibyshevsk, Samara Region, Russian Federation)
}

Abstract. In the paper the author considers the development of medicine in the twentieth century as a factor that significantly changed the morbidity and mortality of the population of the Middle Volga region. The emergence of penicillin and streptomycin, mass vaccination campaigns and promotion of healthy work and life, vector control and advances in medical science, an increase in the number of doctors and hospital beds per capita and affordable free medical care led to a significant reduction in the number of dangerous epidemics in the country. The urban population of the Middle Volga region faced these processes, too. Cases of polio and malaria, anthrax and tularemia, plague and diphtheria, smallpox and cholera were reduced to a few ones, cases of typhus and dysentery decreased significantly, which inevitably led to a shift in the structure of mortality in the region, exogenous mortality factors gave way to endogenous ones. The shift of morbidity towards neoplasm's and cardiovascular diseases was also a trend of the time. And it was the process of «epidemic transition» that occurred in the second half of the last century, as part of the demographic transition, that determined the current trends in morbidity and mortality of the region's population.

Keywords: epidemic transition; infectious diseases; mortality; morbidity; exogenous factors; endogenous factors; quasi-exogenous factors; urban population; Middle Volga region; development of medicine; Soviet medicine; successes of medical science; cardiovascular diseases; demographic transition; morbidity of neoplasms; development of medicine in Russia.

$* * *$

УДК 371 (09)

DOI 10.24411/2309-4370-2020-11214

Статья поступила в редакцию 24.01.2020

\section{РЕФОРМИРОВАНИЕ СИСТЕМЫ ШКОЛЬНОГО ОБРАЗОВАНИЯ В 1958-1964 ГГ.: ЗАДАЧИ И ПРОСЧЁТЫ}

(C) 2020

Репинецкий Александр Иванович, доктор исторических наук, профессор, проректор по научно-исследовательской работе, профессор кафедры отечественной истории и археологии Самарский государственный сочиально-педагогический университет (2. Самара, Российская Федераџия)

Рябов Виктор Васильевич, доктор исторических наук,

профессор, член-корреспондент Российской академии образования,

президент университета, заведующий кафедрой всеобщей и российской истории

Московский городской педагогический университет (г. Москва, Российская Федерация)

Аннотация. Реформирование, проходившее в СССР во второй половине 1950-х - начале 1960-х гг., затронуло и систему образования. В статье рассмотрены причины проведения реформы школьного образования в 
конце 1950-х гг. Проведению реформы предшествовала мощная пропагандистская кампания, главной целью которой было убедить население в необходимости и полезности изменений. Начало реформе положило принятие Закона «Об укреплении связи школы с жизнью и о дальнейшем развитии системы народного образования в СССР». Основные положения реформы средней образовательной школы предполагали создание трудовых политехнических школ, в которых наряду с изучением общеобразовательных предметов ученики должны были получать и рабочую профессию. Срок обучения в средней школе увеличивался на три года (9, 10, 11 классы). Однако, несмотря на подготовку реформы, школа и промышленные предприятия, где должно было проходить производственное обучение, оказались не готовы к его организации. При том, что проводилась широкая агитационная работа, восприятие реформы в обществе было неоднозначным. Ученики и родители не видели смысла в приобретении профессии, по которой они не собирались работать. Реформа не достигла своей главной цели - школа не могла выполнить возложенные на неё несвойственные функции осуществления предпрофессионального обучения учащихся.

Ключевые слова: школьное образование; причины реформирования системы образования; реформа системы образования; производственное обучение; учебно-производственные комбинаты; низшее профессиональное образование; молодежь.

Третье десятилетие продолжается реформирование российской школы. Преобразования проходят под знаком повышения качества образования, приближения его к новым потребностям общества. Но по общему мнению преподавателей вузов и большинства представителей педагогической общественности, в том числе и учителей, реформирование современного образования привело к снижению знаний учащихся, сужению их культурного кругозора. Подругому и быть не могло, если школа получила соответствующий социальный заказ. Бывший министр образования Российской Федерации А.А. Фурсенко (ныне помощник Президента по образовательной политике), выступая на молодёжном форуме «Селигер - 2007» заявил: «Недостатком советской системы образования была попытка формировать человекатворца, а сейчас задача заключается в том, чтобы взрастить квалифицированного потребителя, способного квалифицированно пользоваться результатами творчества других» [1]. Только в последнее время ситуация с задачами образовательной политики начала меняться.

Проблемы развития и реформирования современной школы диктуют и интерес исследователей к предыдущим реформам школьного образования. В частности, особый интерес вызывает реформа образования конца 1950-х гг., когда, с одной стороны, государство четко сформулировало социальный заказ системе советского образования, а с другой навязала школе несвойственные ей функции.

Начало 1940-х гг. характеризуется вступлением развитых стран в четвертый индустриальный технологический этап. Основным ресурсом развития промышленности становятся энергия углеводородов и использование ядерной энергетики. В отечественной прессе происходившие изменения характеризовались термином «научно-техническая революция». Отраслями промышленности, определяющими научно-технический прогресс, становятся автомобилестроение, цветная металлургия, нефтепереработка, производство синтетических полимерных материалов. Развитие этих отраслей требовало нового рабочего, имеющего не только профессиональное образование, но и высокий уровень общего образования.

Первоначально достижения научно-технического прогресса были достоянием лишь ряда отраслей промышленности военно-промышленного комплекса. Активная фаза внедрения достижений науки и техники в производство положило Постановление ЦК КПСС и Совета Министров СССР «Об улучше- нии дела изучения и внедрения в народное хозяйство опыта и достижений передовой отечественной и зарубежной науки и техники» (28 мая 1955 г.). Руководство страны требовало внедрения новых достижений, прежде всего в атомной энергетике, электронике, металлургии [2].

К концу 1950-х гг. уровень образования промышленных рабочих значительно повысился. В отраслях промышленности, определяющих технический прогресс, удельный вес рабочих, не имевших начального образования, составил $15,9 \%$, рабочих с низшим образованием - $16,6 \%$, с семилетним образованием $36,3 \%$ и со средним - 31,2\% [3, с. 187]. Однако производство требовало рабочих со средним общим образованием. По расчетам экономиста В.Г. Афанасьева, успешный переход к автоматизированному производству требовал, чтобы общее среднее образование имели от $40 \%$ до $60 \%$ рабочих в зависимости от производства, пятая часть рабочих имела бы высшее образование, а остальные - семилетнее [4, с. 52]. Особая востребованность лиц со средним образованием наблюдалась на предприятиях военно-промышленного комплекса и машиностроения. К началу 1960-х гг. в этих отраслях насчитывалось 14 профессий высококвалифицированного интеллектуального труда, где рабочий должен был иметь помимо профессионального как минимум общее среднее образования [5, с. 101]. Между тем общее среднее образование имели только около трети рабочих, а рабочий с высшим образованием был крайне редок, и на него смотрели как на явного неудачника. Необходимо было повысить не только профессиональный, но и образовательный уровень рабочих. Эта диспропорция между потребностью и реальностью стала одной из причин проведения реформы образования.

Проблемы повышения уровня общего образования рабочих смыкались с ещё одной острой проблемой - дефицита рабочей силы. Последнее было вызвано тем, что в жизнь вступали дети войны, когда рождаемость резко уменьшилась. Приобретение рабочими среднего общего образования должно было привести к росту производительности труда и уменьшить негативные последствия уменьшения численности рабочих.

Политика государства в области развития образования была направлена на расширение системы среднего и общего образования. В первой половине 1950-х гг. в столицах союзных республик, городах республиканского подчинения, краевых и областных центрах и крупнейших промышленных городах стра- 
ны начался переход к всеобщему среднему образованию. Всего эти процессы были запущены в 120 городах страны [6, с. 240].

Рост лиц со средним образованием привел к появлению новой проблемы: число мест в вузах и техникумах было значительно меньше, чем количество абитуриентов. По официальным данным, только за 4 года (1954-1957 гг.) в вузы и техникумы не поступили 2,5 млн молодых людей [7, с. 12]. Они должны были искать применение своим силам. При этом поступление на промышленные предприятия не входило в планы юношей и девушек, особенно получивших среднее образование. В обществе господствовали представления, что выпускники средних школ должны обязательно получить высшее образование.

Эти настроения хорошо передает пьеса В.С. Розова «В добрый час», а затем и одноименный фильм, снятый по этой пьесе. В центре сюжета - профессорский сын Андрей, который не может определиться с выбором жизненного пути, но твердо знает, что ему необходимо поступить в институт. Рассуждая о поступлении в вуз, он размышляет: «Кто бы за меня словечко замолвил! В ножки бы тому - бултых! Вот клянусь» [8]. В этом его активно поддерживает мать, не допускающая мысли, что сын останется без высшего образования. В духе советской эстетики все заканчивается хорошо - Андрей отказывается поступать в вуз по блату и уезжает вместе со своим двоюродным братом Алексеем на одну из сибирских строек. Конечно, ни пьеса, ни фильм, вышедший на экраны в 1957 г., не могли изменить общественные настроения, но четко угадывали запросы власти. Не помогло и то, что главную роль в фильме сыграл тогдашний кинокумир молодежи Леонид Харитонов.

Эти противоречия между потребностью общества в высокообразованных рабочих и личных интересах молодых людей необходимо было разрешить. Активная фаза подготовки реформы началась с выступления Первого секретаря ЦК КПСС Н.С. Хрущёва на ХХ съезде КПСС (февраль 1956 г.). Руководитель партии заявил: «... необходимо не только ввести в школах преподавание новых предметов, дающих основы знаний по вопросам техники и производства, но и систематически приобщать учащихся к труду на предприятиях, колхозах и совхозах ... и школьных мастерских» [9, с. 82].

В стране начинается мощная кампания по пропаганде физического труда и профессии рабочего. В сентябре 1958 г. газета «Правда» в передовой статье писала: «... многие юноши и девушки, окончившие среднюю школу, признают единственно приемлемым для себя жизненным путем продолжение образования в высших или, в крайнем случае, средних специальных учебных заведениях, неохотно идут работать на фабрики и заводы, в колхозы и совхозы, а некоторые считают оскорблением для себя заниматься физическим трудом... Вместе с тем технический прогресс требует пополнения промышленности и сельского хозяйства молодежью, имеющей достаточно высокую общеобразовательную подготовку» [10].

Обсуждение реформы образования, предусматривающей подготовку молодежи к труду, вылилось в её славословие. Газеты печатали письма читателей, приветствующих предстоящую реформу [7, с. 12].
Зачастую порыв энтузиазма переходил разумные границы. Так, учитель Черемшанской средней школы Татарской АССР Е.С. Кибанов вместе со своим классом после выпуска из школы поехал на строительство Братской ГЭС. Молодые люди освоили рабочие специальности, а учитель стал работать бетонщиком. Официальная пропаганда призывала поддержать данный почин [11]. При этом ни у кого не возникла мысль: а нужны ли стране бетонщики с высшим педагогическим образованием. И этот пример был не единичен.

24 декабря 1958 г. сессия Верховного Совета СССР приняла Закон «Об укреплении связи школы с жизнью и о дальнейшем развитии системы народного образования в СССР». (Закон утратил силу с 1 января 1974 г. в связи с принятием Закона «Основы законодательства Союза ССР и Союзных Республик о народном образовании»). В Законе указывалось, что «ускоренное развитие механизации, автоматизации и химизации производства, широкое применение электроники, счетнорешающих устройств, всемерное развитие электрификации и другие достижения науки и техники коренным образом изменяют характер труда. Труд рабочих и колхозников все более приближается по своему существу к труду инженеров, техников, агрономов и других специалистов. От работников социалистического производства теперь требуется умение обращаться с совершенными станками, точнейшими измерительными, контролирующими приборами и аппаратами, знание сложных технических расчетов и чертежей. ... Разностороннее образование становится для них насущной потребностью» [12]. Далее утверждалось, что, несмотря на процессы автоматизации, физический труд будет сохранен, а «гармоническое развитие человека немыслимо без физического труда» [12].

Первый раздел Закона был посвящен реформированию средней школы, а первая статье раздела четко определяла цель реформы: «Главной задачей советской школы является подготовка учащихся к жизни, общественно полезному труду, дальнейшее повышение уровня общего и политехнического образования, подготовка образованных людей, хорошо знающих основы наук, воспитание молодежи в духе глубокого уважения к принципам социалистического общества, в духе идей коммунизма» [12]. Фактически школы должны были выпускать молодых людей, имеющих минимальный объем политехнических знаний, умений и навыков в области промышленного и сельскохозяйственного производства.

Закон вместо семилетнего образования вводил восьмилетнее. Наиболее существенные изменения касались средней школы. Предусматривалось создание средних общеобразовательных трудовых политехнических школ с производственным обучением. В них выпускники, окончившие восьмилетнюю школу, получали в течение 3 лет среднее образование и профессиональную подготовку для работы в одной из отраслей народного хозяйства. Соотношение теории и практики в производственном обучении и чередование периодов обучения и труда устанавливались в зависимости от профиля специальной подготовки учащихся и от местных условий. Закон предусматривал, что производственное обучение могло проводиться в учебных и производственных цехах 
ближайших предприятий, в ученических бригадах колхозов и совхозов, в учебно-опытных хозяйствах, в школьных и межшкольных учебно-производственных мастерских. Таким образом, на школу возлагалась задача организовать учащимся предпрофессиональное обучение. Как видим, Закон четко определял социальный заказ советской школе, и в этом его положительная роль.

Правительство, свято веря в административные методы руководства, не сомневалось в успехе реформы. Положительная оценка нововведений была присуща не только советской пропаганде. В Аналитической записке НАТО об образовании в СССР, подготовленной в 1959 г. для руководителей этого военного блока, были даны высокие оценки образовательных стандартов советской школы. Аналитики блока посчитали, что предстоящая реформа «... не означает снижения стандартов. Более того, учебная база существующих средних школ без труда может быть адаптирована для выполнения новых целей» [13].

Законодатель считал, что данные нововведения приведут не только к решению задачи обеспечения промышленности квалифицированными и образованными кадрами, но и дадут экономию времени и средств для подготовки современного рабочего. Овладение старшеклассниками рабочей профессией могло проходить несколькими путями: на предприятиях, где для учащихся выделялись специальные рабочие места и мастера производственного обучения. Если это было трудновыполнимо, то обучение проводились в специально созданных производственных комбинатах, а при их отсутствии - в школьных производственных мастерских [14, с. 82].

Несмотря на широкое обсуждение предстоящей реформы и указание закона на постепенность её введения, она оказалась не подготовлена. Государство, как много раз и до этого, уповало на силу приказа. Так, в 1960 г. 52 школы г. Куйбышева занимались в три смены. Занятия старших классов третьей смены заканчивались около 12 часов ночи [15, с. 19]. По официальным данным, большинство учащихся к 1964 г. получали профессиональное образование. В 1963/1964 учебном году в стране работало 13 тыс. политехнических школ, в которых обучалось 1,6 млн учащихся 9-11 классов, что составило $96 \%$ от общего числа учащихся [16, с. 470].

Эта ситуация делает понятным, почему во многих школах отсутствовали производственные мастерские, а в имеющихся было невозможно разместить современное промышленное оборудование.

Производственные комбинаты, которые должны были быть созданы после принятия Закона, поставили перед местными властями сложные задачи: найти помещение, оснастить его необходимым оборудованием. Первая проблема зачастую решалась путем передачи под производственный комбинат одного из школьных зданий. Это приводило к перенаполнению учащимися и без того перегруженных школ. Оборудование производственным комбинатам должны были выделить промышленные предприятия. Последние отправляли в комбинаты устаревшее оборудование, и никакие распоряжения не могли заставить их изменить эту политику.

К реформе оказались не готовы и промышленные предприятия. Создание для школьников рабочих мест и их оборудования, выделение мастеров производственного обучение была весьма обременительной задачей. Руководители предприятий не стремились её реализовать, тем более уверенности, что обученные старшеклассники будут работать по полученной специальности на данном предприятии, не было.

По подсчетам авторов работы, в начале 1960-х гг. в таком крупном промышленном регионе, как Поволжье, промышленные предприятия могли обеспечить рабочими местами только 58\% старшеклассников [3, с. 191]. Выход из ситуации власти искали путем привлечения к реализации реформы общественности. В начале 1960-х гг. были созданы общественные советы по производственному обучению. В них были включены представители органов власти, промышленных предприятий, работники образования. Советы разрабатывали планы по расширению производственного обучения и повышению его качественного уровня. Конечной целью планов было достижение количественных показателей, а именно обеспечение рабочими местами всех учащихся старших классов. Деятельность советов, безусловно, способствовала улучшению производственного обучения. К середине 1960-х гг. на предприятиях г. Куйбышева (ныне г. Самара) действовал 21 учебный цех и 48 производственных участков, г. Казани - 14 цехов и 45 производственных участков [17]. Главный недостаток деятельности общественных советов был в отсутствии их финансирования, что приводило к невыполнению принимаемых решений. Во многом успехи в осуществлении реформы зависели от настойчивости представителей власти и доброй воли руководителей промышленных предприятий.

Еще одной так и не решенной проблемой реформы был узкий список профессий, которые молодой человек мог получить в период производственного обучения. Молодежь впитывала пропаганду успехов научно-технического прогресса и внедрение его достижений в производство. Молодые люди мечтали работать на станках с программным обеспечением, автоматических линиях. Действительность разбивала эти мечты. Профессиональная подготовка полностью зависела от имеющегося оборудования. А оно позволяло готовить к малопривлекательным в глазах молодежи профессиям: слесарь, столяр, жестянщик, шофер, швея-мотористка. Пожалуй, только профессия шофера пользовалась популярностью у старшеклассников. Значительно реже встречались такие профессии, как токарь-универсал, наладчик, электромонтер. Желание учеников при выборе профессии не учитывалось - выбирать в лучшем случае предполагалось из двух-трех профессий, которые мог предложить производственный комбинат.

Отсутствие необходимых рабочих мест заставляло руководителей образовательных учреждений изыскивать различные способы для привлечения учащихся к производственному труду. Так, для выполнения задач производственного обучения 20\% учащихся ленинградских школ участвовали в ремонте школьных зданий и мебели, работали подсобными рабочими на стройках $[18$, с. 128]. При этом говорить об овладении ими рабочей специальностью не приходится. Нельзя не отметить и то, что в условиях про- 
фессионального обучения на руководителей школ возлагалась дополнительная ответственность за обеспечение безопасности и здоровья учащихся.

Газеты печатали победные реляции об успехах реформы, рассказывали о выпускниках средних школ, поступивших на работу на предприятия, приводили их высокие оценки реформы. Постепенно проходило расширение объемов производственного обучения, что повысило удельный вес учащихся, овладевших рабочей профессией. Уже через 2 года после принятия Закона в европейской части страны производственным обучением было охвачено 78\% старшеклассников [19]. Постоянно увеличилась и доля выпускников средней школы, поступивших на производство. И с этой точки зрения можно сказать, что реформа привела к положительным результатам.

Однако полного осуществления задач реформы добиться не удалось. Парадокс заключался в том, что молодые люди, пришедшие на производство, не использовали профессиональные навыки, полученные в школе. По подсчетам исследователей, профессия, полученная в школе, оказалась не нужна 9 выпускникам из 10 человек, пришедших на производство [20, c. 48].

Передача профессионального образования в среднюю школу не решила проблему подготовки квалифицированных кадров для промышленности. Средства, потраченные на организацию низшего профессионального образования в рамках среднего общего образования, фактически не принесли желаемого эффекта. Господствующее в обществе настроение, что выпускники средней школы должны получать высшее или, на крайний случай, среднее специальное образование, переломить не удалось.

Реформа, несмотря на массив восхваляющих её публикаций, вызвала негативное отношение в обществе. Профессиональное образование занимало два дня, а иногда и три дня в неделю. Конкурсы в высшие учебные заведения постоянно росли. И время, затраченное на овладение профессией, а на него отводилась практически треть учебных часов, рассматривалось родителями как бесцельно потраченное, отвлекающее детей от серьезных занятий. Такого же мнения были и большинство старшеклассников, нацеленных на поступление в вуз. Тем более, овладение рабочей профессией в школе не давало никаких преимуществ при поступлении в университеты и институты. Для получения льгот было необходимо иметь два года стажа работы в промышленности или сельском хозяйстве. Недовольство реформой крайне осторожно высказывали и учителя. Общественное мнение было однозначно: реформа привела к снижению образовательного потенциала выпускников школ. К середине 1960-х гг. просчеты реформы стали видны всему обществу. После отстранения от власти её творца Н.С. Хрущёва (1964 г.) реформа начала сворачиваться и практически перестала реализовываться. Косвенно о потере интереса к реформе говорит тот факт, что в статистическом сборнике «Народное хозяйство РСФСР в 1964 году» данных о политехнических школах и обучающихся в них отсутствуют [21].

Опыт проведения реформы 1958-1964 гг. показал, что реформирование образования требует тща- тельной подготовки. Реформа показала, что главная задача общеобразовательной школы - давать знания. Навязывание школе выполнения несвойственных ей функций обречено на провал, какими бы потребностями общества они ни диктовались.

\section{Список литературы:}

1. О системе образования [Электронный ресурс] // ЛитМир. - https://www.litmir.me/bd/?b=592025.

2. Политбюро ЦК ВКП(б) и Совет министров СССР, 1945-1953 / сост.: О.В. Хлевнюк [и др.]. М.: РОССПЭН, 2002. 654 c.

3. Репинецкий А.И. Работники промышленности Поволжья: демографический состав, образовательный и профессиональный уровень. 1946-1965 гг. Самара: Науч.-техн. центр, 1999. 402 с.

4. Афанасьев В.Г. Научно-техническая революция, управление, образование. М.: Политиздат, 1972. $431 \mathrm{c}$.

5. Ковригин М.А. Обновление рабочих кадров. М.: Мысль, 1989. 222 с.

6. История СССР: С древнейших времен до наших дней. В 2-х сер. В 12-ти т. Т. 11. Советский Союз на пути к развитому социализму, 1945-1961 гг. / И.Б. Берхин, Н.Я. Бромлей, С.И. Висков и др. М.: Наука, 1980. 653 с.

7. Всенародное обсуждение вопроса об укреплении связи школы с жизнью и о дальнейшем развитии системы народного образования в стране: материалы, опублик. в газете «Правда» (с 16 ноября по 15 декабря 1958 г.). М.: Правда, 1958. 288 с.

8. Розов В.С. В добрый час! Комедия в 4 д., 5 карт. М.: Искусство, 1959. 118 с.

9. ХХ съезд Коммунистической партии Советского Союза: Стенографический отчёт. 14-25 февраля 1956 г. В 2 т. Т. 1. М.: Госполитиздат, 1956. 640 с.

10. Передовая статья // Правда. 1958. 12 сентября.

11. На стройку коммунизма // Правда. 1958. 30 ноября.

12. Закон об укреплении связи школы с жизнью и о дальнейшем развитии системы народного образования в СССР. М.: Известия, 1958. 31 с.

13. Scientific and Technological Training and Manpower in the USSR [Internet] // https://archives.nato.int/ uploads/r/null/6/1/6109/AC_137-D_40_ENG.pdf.

14. Волошина О.Б. Учительство Куйбышевской области (вторая половина XX века) // Вояджер: мир и человек. 2016. № 7. С. 73-88.

15. Романова Г.А. Реформирование системы школьного образования в 1958-1064 гг. (на материалах Куйбышевской области): автореф. дис. ... канд. ист. наук. Самара, 2003. 24 с.

16. Народное хозяйство РСФСР в 1963. Статистический сборник. М.: Госстатиздат, 1965. 600 с.

17. Государственный архив Российской Федерации (ГАРФ). Ф. А374. Оп. 32а. Д. 2920. Л. 14-64.

18. Полотебнов А.С. Образовательная реформа 1958-1964 годов: Ленинградский опыт реализации // Человек и образование. 2017. № 1 (50). С. 127-131.

19. ГАРФ. Ф. АЗ74. Оп. 23. Д. 2920. Л. 10-69.

20. Руткевич М.Н., Рубина Л.Я. Общественные потребности, система образования, молодёжь. М.: Политиздат, 1988. 222 с.

21. Народное хозяйство РСФСР в 1964 году. Статистический сборник. М.: Госстатиздат, 1965. 576 с. 


\title{
THE SCHOOL SYSTEM REFORM IN 1958-1964: CHALLENGES AND MISCALCULATIONS
}

(C) 2020

Repinetskiy Aleksandr Ivanovich, doctor of historical sciences, professor, vice rector for research work, professor of Domestic History and Archeology Department Samara State University of Social Sciences and Education (Samara, Russian Federation)

Ryabov Viktor Vasilevich, doctor of historical sciences, professor, corresponding member of Russian Academy of Education, president of University, head of World and Russian History Department Moscow City University (Moscow, Russian Federation)

\begin{abstract}
The paper considers the reasons for the educational system reform in the late 1950s, which began with the adoption of the law «Strengthening the connection of school with life and further development of the national educational system in the USSR». The main propositions of the secondary school reform included labor polytechnic schools establishments where students were supposed to get profession along with the study of general education subjects. The period of study at a secondary school was supposed to be three years (grades 9, 10,11). Schools and industrial enterprises where industrial training was to take place were not ready to organize industrial training. Despite the extensive campaign, the perception of the reform in society was controversial. The reform did not achieve its main goal - schools could not carry out pre-professional education of students.

Keywords: school education; educational system reform; industrial training; industrial practice plants; youth.
\end{abstract}

\section{ВОЕННЫЙ ПЕРЕВОРОТ В ТУРЦИИ 27 МАЯ 1960 ГОДА: ПРЕДПОСЫЛКИ, ДВИЖУЩИЕ СИЛЫ И ПОСЛЕДСТВИЯ}

Товсултанова Малика Шариповна, аспирант кафедры новой и новейшей истории

Товсултанов Рустам Алхазурович, кандидат исторических наук, доцент кафедры новой и новейшей истории

Чеченский государственный университет (2. Грозный, Российская Федераиия)

Галимова Лилия Надиповна, доктор исторических наук, доцент, профессор кафедры гуманитарных и социально-экономических дисциплин Ульяновский институт гражданской авиаџии имени Главного мариала авиаџии Б.П. Бугаева (2. Ульяновск, Российская Федерачия)

Аннотация. В 1950-е годы к власти в Турции пришла оппозиционная Демократическая партия, опиравшаяся на провинциальную буржуазию и клерикалов. Премьер-министром стал её харизматичный Аднан Мендерес. Правительство демократов проводило активную внешнюю и внутреннюю политику. В частности, отказавшись от традиционного нейтралитета, Турция вступила в военные блоки НАТО и СЕНТО. Были сделаны уступки религиозным кругам. Правительство также проводило масштабные реформы, к которым общество было не готово, ввиду чего в стране разразился экономический кризис, самым характерным проявлением которого была высокая инфляция. Введением репрессивных законов против инакомыслящих, попытки изолировать оппозицию, в частности лидеров Народно-республиканской партии (НРП), демократы подтолкнули последних к поиску союзников в армии. В рядах последней под влиянием западной агентуры и недовольства самих офицеров ситуацией в стране возникла идея военного переворота, который произошёл 27 мая 1960 г. В результате переворота к власти пришёл Комитет национального единства, состоявший из представителей генералитета и лидеров Народно-республиканской партии. В 1961 году на референдуме была принята новая конституция, реформировавшая систему законодательной власти в стране, после чего власть вновь перешла к гражданским политическим институтам. Лидер военных, осуществивших переворот, генерал Джемал Гюрсель занял пост премьер-министра, а председатель НРП Исмет Инёню стал президентом Турции.

Ключевые слова: Турция; военный переворот; 27 мая 1961 года; Демократическая партия; Мендерес; Народно-республиканская партия; Ататюрк; реформы; кемализм; оппозиция; инфляция; протесты; «Гладио»; «Контргерилья»; Комитет национального единства; конституция; референдум; Гюрсель; Инёню; Тюркеш; кризис; инфляция; референдум; конституция.

Попытка военного переворота в Турции в июле 2016 года вновь привлекла внимание исследователей к проблеме природы, экономических и политических предпосылок, механизмов и движущих сил военных переворотов второй половины XX в. в этой стране. В свою очередь, действующий турецкий президент Р.T. Эрдоган неоднократно публично с симпатией отзывался о лидере свергнутой военными в 1960 г.
Демократической партии премьер-министре Аднане Мендересе [1]. Переворот 27 мая 1960 г. был первым в череде выступлений военных и во многом определил их последующий сценарий, что делает анализ его исторического контекста особенно актуальным.

В последние годы вышло немало работ, посвящённых событиям конца 1950 - начала 1960-х годов на турецком, русском и английском языках. Отметим 